\title{
Study and Assessment of the Efficiency of the Cocoa Bark Extracted from the Theobroma Cacao as an Inhibitor of the Corrosion of Carbon Steel in Substitution of Benzotriazole
}

\author{
Lhaira Souza Barreto ${ }^{a}$,Miriam Sanae Tokumoto , Isabel Correia Guedes ${ }^{b}$,Hercilio Gomes de Meloc, \\ Franco Amado ${ }^{a}$, Vera Rosa Capelossi ${ }^{a} *$ \\ ${ }^{a}$ Departamento de Ciências e Tecnologia, Universidade Estadual de Santa Cruz, Rodovia Jorge Amado, \\ Km. 16, CEP 45.662-900, Salobrinho, Ilhéus, BA, Brazil \\ ${ }^{b}$ Departamento de Engenharia Química, Escola Politécnica, Universidade de São Paulo, Av. Professor \\ Luciano Gualberto, 380, Cidade Universitária, CEP 05508-900, São Paulo, SP, Brazil \\ ${ }^{c}$ Departamento de Engenharia Metalúrgica e de Materiais, Escola Politécnica, Universidade de São \\ Paulo, Av Professor Mello Moraes, $n^{\circ}$. 2463, CEP 05508-030, São Paulo, SP, Brazil
}

Received: April 18, 2016; Revised: August 09, 2017; Accepted: October 26, 2017

\begin{abstract}
Corrosion represents high losses to the economy, therefore, researches on the minimization of its damages in materials, mainly the metallic ones, are necessary. Among the various alternatives of protection against corrosion, there is the application of corrosion inhibitors that can minimize or even stop the corrosive process of metallic materials. However, at present, substances usually used as corrosion inhibitors present high toxicity, being considered harmful components to the environment and to human health. Therefore, there is an urgent need for studies on viable corrosion inhibitors, by considering not only economic but also environmental costs. The present work studied the use of cocoa bark extract (Theobrama cacao $L$ ), for possible replacement of benzotriazole (BTAH) in the corrosion inhibition of ASTM 1020 carbon steel (CS- ASTM 1020) in 18.23 g.L.-1 hydrochloric acid media. Weight loss measurements, anodic and cathodic potentiodynamic polarization curves and electrochemical impedance experiments were carried out. The results showed that the addition of the extract to the electrolyte effectively hinder the corrosion process and indicated its adsorption on the electrode surface. In addition, the inhibiting efficiency of the cocoa bark extract was only slightly inferior to BTAH, showing that it can be an environmentally friendly option to toxic inhibitors.
\end{abstract}

Keywords: Corrosion inhibitor, corrosion, EIS, benzotriazole, Theobrama cacao L.

\section{Introduction}

Acidic solutions are widely used in several industries, mainly in acid pickling, oil wells, cleaning and decalcification, leading to corrosive attack of metals. One of the most widespread and inexpensive ways to control metallic corrosion in such applications is by using corrosion inhibitors. Compounds such as chromates, phosphates and benzotriazole (BTAH) have being efficiently employed to mitigate corrosion damage in acidic media ${ }^{1-3}$. However, due to their toxicity and environmental impact, in the last decade, substitution of these compounds by corrosion inhibitors derived from plants, i.e. natural corrosion inhibitors, has become a major issue of interest to minimize metallic corrosion in acidic media ${ }^{4-8}$.

BTAH is widely used as corrosion inhibitor due to its ability to form a protective film on different metallic materials and the literature demonstrates that it can effectively hinder steel corrosion in several media ${ }^{9,10,11}$. However, currently, there are controversies regarding the toxicity of this inhibitor towards humans and the environment ${ }^{12}$. Therefore, industries and researchers are broadening their efforts to develop

*E-mail: vera.rosa@gmail.com corrosion inhibitors formulations presenting low toxicity and good efficiency.

The efforts to find natural corrosion inhibitors have gained notoriety because they are easily available, biodegradable and sustainable, present low-cost and do not have toxic compounds. In the search for more environmentally acceptable formulations, researchers have reported promising results with extracts obtained from pepper, cocoa, mango, avocado, cabbage, weeds, potatoes, mug wort and guar gum for different metals and media-8;13-18. Typically, inhibition efficiencies superior to $90 \%$ has been reported at optimized conditions. The good performance of these natural inhibitors has been ascribed to the presence of organic functionalities such as tannins, alkaloids, nitrogen base, carbohydrates and proteins with antioxidant properties ${ }^{19,20}$.

The species Theobroma cacao L. belongs to the Stercu liaceae family. Known as cocoa tree, it is natural of tropical regions of the American rainforest and it is intensively cultivated in the south of Bahia state, Brazil. During the industrialization process, cocoa is not fully used. The discards achieve approximately $80 \%$ of the processed material, corresponding to the bark. Bravo ${ }^{21}$ highlights that cocoa 
is rich in total polyphenols, which are a class of phenolic compounds that occur in fruits, seeds and flowers. Phenolic groups have antioxidant properties derived from their redox potentials that allow them to act as reducing agents, providing hydrogen and neutralizing free radicals.

Considering the interest to preserve carbon steel and to obtain low-toxicity inhibitors from vegetables residues, this study is focused on the assessment of the corrosion inhibition potentiality of a natural corrosion inhibitor obtained from the residues of Theobroma cacao processing, the cocoa bark extract, for the replacement of benzotriazole (BTAH) to protect 1020 carbon steel corrosion in $\mathrm{HCl}$.

It is important to emphasize that, to the authors' knowledge, there is no report in the literature about the effectiveness of cocoa residues as corrosion inhibitor for metals in acidic media. Therefore this an original contribution in this specific domain. The only report found on similar subject was about positive inhibitory efficacy of polyphenol groups extracted from cocoa liquor towards tin corrosion in food media, which was published in a conference paper ${ }^{22}$.

\section{Experimental}

The investigation was performed with 1020 carbon steel (CS - ASTM 1020) immersed in $\mathrm{HCl} 18.23 \mathrm{~g} \mathrm{~L}^{-1}$ (anidrol) without and with inhibitor. Prior to any test, the samples surfaces were sequentially ground with 120, 320,400, 600, 800,1200 and 2000 sand paper and then washed with distilled water, ethanol and acetone and dried with a hot air stream.

The extract was prepared by washing cocoa bark with distilled water and drying in an oven at $70^{\circ} \mathrm{C}$ for $60 \mathrm{~min}$. Next, the dried samples were milled, to reduce the particle size to a powder, and immersed in ethanol at room temperature for 48 $\mathrm{h}$. The mixture was then filtered and the concentrated extract produced using a rotary evaporator at $79{ }^{\circ} \mathrm{C}$ to remove the excess solvent, resulting in the extract powder. Preliminary tests were carried out using two different concentrations of the bark cocoa extract: $0.778 \mathrm{~g} \mathrm{~L}^{-1}$ and $1.112 \mathrm{~g} \mathrm{~L}^{-1}$. The results obtained with the best inhibiting efficiency were compared with that found in solutions containing the same amount of Benzotriazole (BTAH).

Weight loss tests were performed according to ASTM G1-03 standard ${ }^{23}$ using rectangular electrodes ( $\left.50 \times 20 \times 0.8\right)$ $\mathrm{mm}$. Weighing was carried out after $120 \mathrm{~min}$ immersion, after the samples have been washed with distilled water, alcohol and acetone. Experiments were performed in triplicate in unstirred solution.

Electrochemical impedance spectroscopy (EIS) experiments were carried out to using a potentiostat/galvanostat Metrohm Autolab PGSTAT 302N, equipped with an impedance modulus and controlled with the NOVA 1.11 software. The diagrams were acquired at the open circuit potential (OCP) after 90 min using a classical three electrodes cell. Round-shaped (1.0 $\mathrm{cm}^{2}$ ) CS-1020 samples were employed as working electrodes with a Rh-coated $\mathrm{Ti}$ wire as auxiliary electrode and an $\mathrm{Ag}$ / $\mathrm{AgCl}|| \mathrm{KClSat}$ reference electrode. The data were obtained from $100 \mathrm{kHz}$ to $10 \mathrm{mHz}$, with 10 points per decade using a perturbation amplitude of $10 \mathrm{mV}$. For quantitative analyses, EIS data were fitted with the Zview software.

Anodic and cathodic polarization curves were acquired from $\mathrm{OCP} \pm 250 \mathrm{mV}$ subsequently to the EIS measurements and after 5 min of stabilization of the OCP, making the exposure time similar to that used in the weight loss measurements. Experiments were performed at a scan rate of $0.5 \mathrm{mV} \mathrm{s}^{-1}$. The waiting time was necessary in order to verify that the electrode potential had returned to the steady state value.

Micrographs of the electrodes surface were taken after 90 min immersion in the test electrolyte (EIS experiments) or 120 min (weight loss measurements) with and without the inhibitors using a scanning electron microscope (SEM) Quanta 250F after weight loss measurements and EIS experiments.

The chemical characterization of the bark cocoa extract and BTAH powders was performed by infrared spectroscopy (FTIR) using a Thermo Scientific Nicolet spectrometer model is 10. Spectra were recorded at room temperature in the wave number range $4000-400 \mathrm{~cm}^{-1}$ at a resolution of $4 \mathrm{~cm}^{-1}$. The powders were analysed using $\mathrm{KBr}$ pellets.

\section{Results and Discussions}

\subsection{Chemical characterization}

\subsubsection{Fourier transformed infrared spectroscopy (FTIR)}

Figures 1 and 2 show, respectively, the FTIR spectra of the cocoa bark extract and of the BTAH powder.

The spectrum of the cocoa bark extract (Fig. 1) has a strong absorption band at $3445 \mathrm{~cm}^{-1}$. This band, not present in the BTAH spectrum (Fig. 2), is ascribed to $\mathrm{OH}$ stretching, indicating that the ethanol used in the extraction procedure was not fully eliminated. According to Gomes ${ }^{7}$, hydroxyl groups facilitate the adsorption of substances on metallic surfaces because they tend to form hydrogen bonds with free radicals of compounds made of carbon, nitrogen, and sulphur. Specific bands ascribed to nitrogen containing compounds were also detected at $1520 \mathrm{~cm}^{-1}(\mathrm{C}=\mathrm{N})$, and at $621 \mathrm{~cm}^{-1} \mathrm{NH}_{3}$ in the spectrum. According to Zucchi et al. ${ }^{24}$, organic compounds containing nitrogen can act as corrosion inhibitor due to their antioxidant properties.

A fully identified FTIR spectrum for BTAH is presented in Figure 2. Being a pure compound, peaks assignments were easier than for cocoa bark extract. In the spectrum the most relevant bands are those observed at 1206, 777 and $737 \mathrm{~cm}^{-1}$, corresponding to the $\mathrm{C}-\mathrm{H}$ in-plane bending and $\mathrm{C}-\mathrm{H}$ out-of-plane bending vibrations of the benzotriazole benzene ring. At $1100 \mathrm{~cm}^{-1}$ there is another important peak that can be attributed to the stretching of benzene and triazole rings, corresponding also to N-H stretching. 


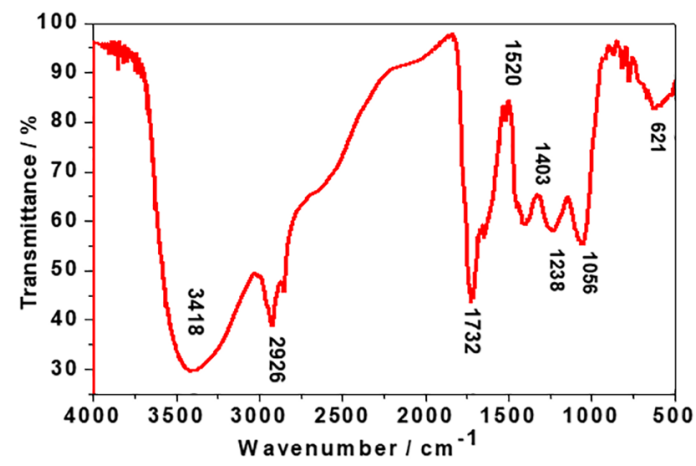

Figure 1. FTIR spectrum of the cocoa bark extract.

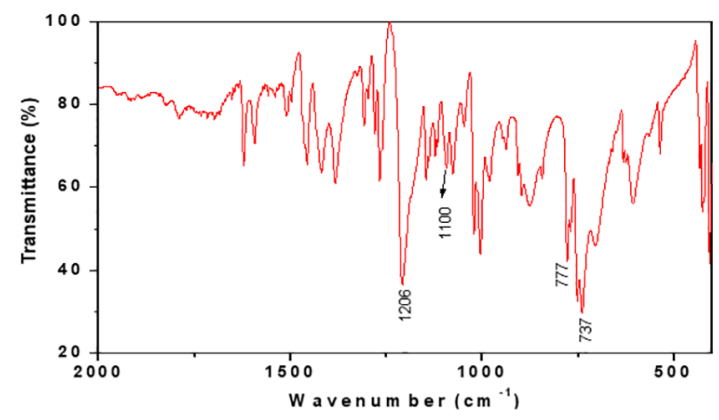

Figure 2. FTIR spectrum of the Benzotriazole powder.

The chemical characterization of the cocoa bark extract and of the BTAH powder obtained by FTIR (Figs. 1 and 2) revealed the presence of nitrogen, which functionalities can act as corrosion inhibitor ${ }^{7,25}$. However, the bands associated to nitrogen are more intense for BTAH than for cocoa bark extract, which eventually may justify a greater efficiency for the former inhibitor.

\subsection{Gravimetric methods}

The inhibition efficiency (IE) and the corrosion current density were determined from gravimetric tests after $120 \mathrm{~min}$ immersion in the different electrolytes. IE was calculated from Eq. (1), where $W_{\text {corr }}$ (wo) and $W_{\text {corr }}$ (w) correspond, respectively, to the weight loss without and with the inhibitor ${ }^{26}$ :

$$
I E=\frac{W_{\text {corr }(\mathrm{wo})}-W_{\operatorname{corr}(\mathrm{w})}}{W_{\operatorname{corr}(\mathrm{wo})}} x 100
$$

Whereas the corrosion current density was determined from Eq. (2):

$$
i_{\text {corr }}=w_{\text {corr }} \frac{96500}{E_{\text {qmetal }}}
$$

where $i_{\text {corr }}$ is the corrosion current density $\left(A \mathrm{~cm}^{-2}\right), w_{\text {corr }}$ the corrosion rate $\left(\mathrm{g} \mathrm{cm}^{-2} \mathrm{~h}^{-1}\right), 96500$ the Faraday's constant (A s) and $E_{\text {qmetal }}$ the equivalent gram of iron, $27.939 \mathrm{~g}^{26}$.

The results of the weight loss determinations after the completion of the experiments, together with the values calculated from Eq. (1) and (2) are summarized in Table 1.
They evidence that corrosion of CS occurs when immersed in $18.23 \mathrm{~g} \mathrm{~L}^{-1} \mathrm{HCl}$ solution; however, the process is minimized in the presence of the inhibitors. Concerning the cocoa bark extract, it can be verified that the weight loss, and, consequently, the corrosion current density, decreases when higher amount is added to the electrolyte. Such behavior may be justified by the presence of antioxidant molecules in the cocoa bark extract that adsorb in the substrate surface, thus retarding the corrosive process. ${ }^{8}$

The fifth column of Table I display the inhibition efficiency (IE) calculated from the weight loss measurements according to Eq. (1). It can be verified that, for the same amount of inhibitor, BTAH is slightly more efficient than the cocoa bark extract. However, taking into account that the composition of the extract must be quite complex, it can be supposed that active inhibitors components of the extract must be very effective. Regarding the determined inhibiting efficiency, that for BTAH is in accordance with published results ${ }^{6}$, whereas for the cocoa bark extract no data is available in the literature for acidic media. However, as already stressed in the introduction, the $I E$ achieved with the cocoa bark extract is similar to those reported for natural inhibitors obtained from plants extracts ${ }^{13-18}$.

\subsection{Electrochemical techniques}

\subsubsection{Electrochemical impedance spectroscopy (EIS)}

Electrochemical tests were carried out in the absence and in the presence of the inhibitors after $90 \mathrm{~min}$ of OCP stabilization. Figure 3 presents the EIS diagrams acquired under these conditions for different amounts of cocoa bark extract added to the electrolyte. Independently of the presence of the inhibitor, the Nyquist diagram is composed by a single depressed capacitive loop, indicating that, whatever the solution composition, the corrosion mechanism remains the same ${ }^{26,27}$. The results also evidence that the addition of the inhibitor to the $\mathrm{HCl}$ solution increases the impedance response of CS, indicating enhanced corrosion resistance, and that the inhibitive effect increases with inhibitor amount. Such improvement in the corrosion resistance may be attributed to increased adsorption of molecules with inhibitory properties on the substrate surface ${ }^{6,15,16}$ forming a more protective layer ${ }^{7}$ that hinders the evolution of the corrosive process. In Figure $3 b$, it can be observed that the phase angle maximum is slightly displaced to higher frequencies when cocoa bark extract is added to the test electrolyte. This result, according to Markhali et al. ${ }^{28}$, may be related to the diminution of the dielectric constant of the electric double layer, due to the adsorption to the electrode surface of organic molecules with inhibitory properties present in the cocoa bark extract. In addition, when the inhibitor was added to the electrolyte, the Nyquist diagram as well as the phase angle plot become more symmetrical, indicating that the electrode response is closer to an ideal behavior. 
Table 1. Weight loss of CS - ASTM 1020 after 120 min immersion in $18.23 \mathrm{~g} \mathrm{~L}^{-1} \mathrm{HCl}$ solution in the absence and in the presence of inhibitors

\begin{tabular}{|c|c|c|c|c|c|c|}
\hline \multicolumn{5}{|c|}{ Weight loss experiments } & \multicolumn{2}{|c|}{ Polarization curves } \\
\hline Medium & Variation(g) & $\begin{array}{c}W_{\text {corr }} \\
\left(\mathrm{g} \mathrm{cm}^{-2} \mathbf{h}^{-1}\right)\end{array}$ & $\begin{array}{c}i_{\text {corr }} \\
\left(\mathrm{A} \mathrm{cm}^{-2}\right)\end{array}$ & $\begin{array}{l}I E \\
(\%)\end{array}$ & $\begin{array}{c}i_{\text {corr }} \\
\left(\mathrm{A} \mathrm{cm}^{-2}\right)\end{array}$ & $\begin{array}{l}I E \\
(\%)\end{array}$ \\
\hline $\begin{array}{l}\text { Without } \\
\text { inhibitor }\end{array}$ & $1.3010^{-2}$ & $5.4310^{-4}$ & $5.2110^{-4}$ & - & $110^{-4}$ & - \\
\hline $\begin{array}{l}0.778 \mathrm{~g} \mathrm{~L}^{-1} \\
\text { extract }\end{array}$ & $1.7010^{-3}$ & $7.0810^{-5}$ & $6.7710^{-5}$ & 87 & $210^{-5}$ & 80 \\
\hline $\begin{array}{l}1.112 \mathrm{~g} \mathrm{~L}^{-1} \\
\text { extract }\end{array}$ & $9.3310^{-4}$ & $3.8910^{-5}$ & $3.7410^{-5}$ & 93 & $1.110^{-5}$ & 89 \\
\hline $\begin{array}{l}1.112 \mathrm{~g} \mathrm{~L}^{-1} \\
\text { BTAH }\end{array}$ & $6.3310^{-4}$ & $2.6410^{-5}$ & $2.5310^{-5}$ & 95 & $0.810^{-5}$ & 90 \\
\hline
\end{tabular}
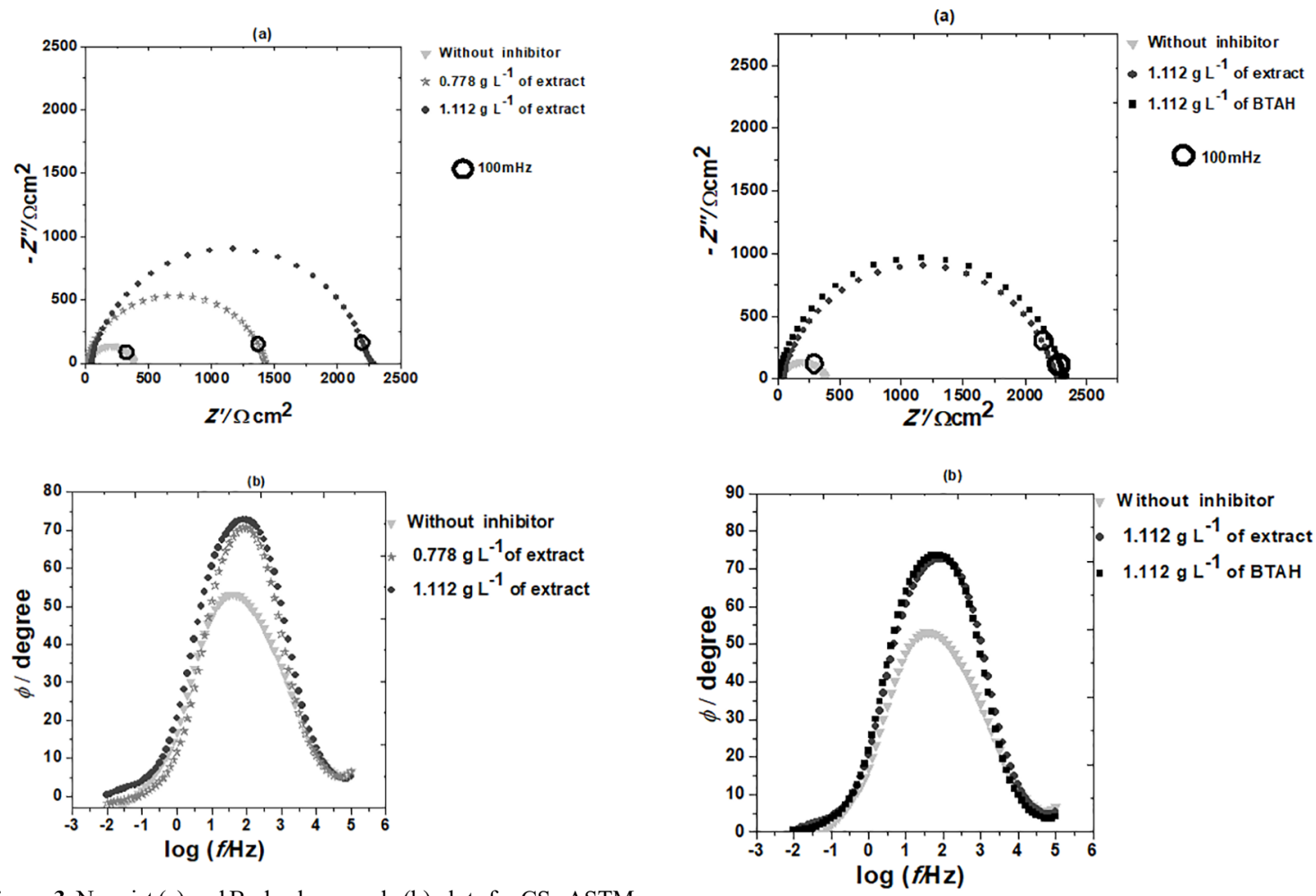

Figure 3. Nyquist (a) and Bode phase angle (b) plots for CS - ASTM 1020 after 90 min immersion in $\mathrm{HCl} 18.23 \mathrm{~g} \mathrm{~L}^{-1}$ in the absence and in the presence of different amounts of cocoa bark extract.

By comparing the EIS diagrams acquired in the solutions containing $1.112 \mathrm{~g} \mathrm{~L}^{-1}$ either of cocoa bark extract or of BTAH (Figure 4a), it can be observed that the sample immersed in the BTAH containing solution presents a slightly higher impedance, indicating stronger interactions between these latter molecules and the substrate surface. Nevertheless, due to the complex composition of the cocoa bark extract (not disclosed in the present work) it is likely that the effective

Figure 4. Nyquist (a) and Bode phase angle (b) plots for CS - ASTM 1020 after $90 \mathrm{~min}$ immersion in $\mathrm{HCl} 18.23 \mathrm{~g} \mathrm{~L}^{-1}$ in the absence and in the presence of $1.112 \mathrm{~g} \mathrm{~L}^{-1}$ of inhibitors.

concentration of potentially inhibiting species should be smaller in the solution containing this inhibitor than in the BTAH containing one, indicating a very effective protection capability.

To have a better quantitative analysis of the overall impedance behaviour, the EIS diagrams of Figure 4 were fitted using an electric equivalent circuit (EEC) (Figure 5) 


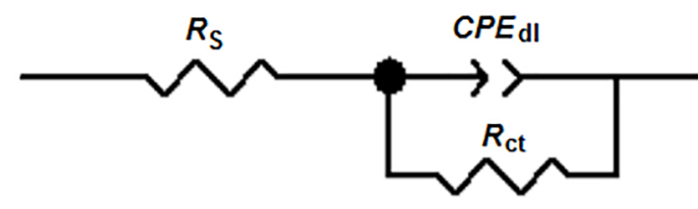

Figure 5. Electrical equivalent circuit used to fit the EIS results of CS-ASTM 1020 in $18.23 \mathrm{~g} \mathrm{~L}^{-1} \mathrm{HCl}$ solution in the absence and in the presence of $1.112 \mathrm{~g} \mathrm{~L}^{-1}$ inhibitors.

usually employed to model the impedance response of steel in acidic solutions without or with inhibitors ${ }^{27,29,30,31,32}$. In the circuit, $R_{\mathrm{s}}$ stands for the solution resistance, $R_{\mathrm{ct}}$ represents the charge transfer resistance and $C P E_{\mathrm{dl}}$ is a constant phase element representing the double layer charging, which accounts for frequency dispersion in the EIS response, usually ascribed to physical phenomena like roughness or non-homogeneity of the surface ${ }^{32}$. The impedance of a $C P E$ is defined by Eq. (3), wherein $Q$ is the $C P E$ constant, $\omega$ is the angular frequency $\left(\operatorname{rad} . \mathrm{s}^{-1}\right), i^{2}=-1$ is the imaginary number and $\alpha$ is the $C P E$ exponent ${ }^{26}$. Table 2 presents the results of the fitting procedure.

$$
Z_{C P E}=Q^{-1}(i \omega)^{-\alpha}
$$

When the EIS response of an electrode is characterized by a single capacitive loop, $R_{\mathrm{ct}}$ is directly proportional to the corrosion resistance, then, the bigger $R_{\mathrm{ct}}$, and consequently the loop diameter, the higher the corrosion resistance. Table 2 shows that $R_{\mathrm{ct}}$ increases when inhibitors are added to the solution. Therefore, the data presented in this table confirm that both inhibitors effectively hinder CS corrosion in acidic medium.

The corrosion inhibition efficiencies $(I E)$ presented in Table 2 were calculated using Eq. (4), wherein $R_{\text {Tinb }}$ and $R_{\text {Tco }}$ are the charge transfer resistances with and without inhibitor, respectively ${ }^{6}$. The calculated values were $81.3 \%$ for the cocoa bark extract and $82.3 \%$ for the BTAH containing solutions, confirming that this latter inhibitor has a slightly better protective performance. For both inhibitors, $I E$ was lower than that determined by the gravimetric method, even though, the tendency remains the same. A possible reason to explain this relative high difference between the two methodologies could be the immersion time, which for the EIS experiments was $75 \%$ from that employed in the weight loss measurements.

$$
I E \%=\frac{R_{\mathrm{Tinb}}-R_{\mathrm{Tco}}}{R_{\mathrm{Tinb}}} \times 100
$$

The values reported in Table 2 show that the $C P E$ exponent $(\alpha)$ increases when the inhibitor is added to the test electrolyte, evidencing a more ideal behavior ${ }^{27}$. However, the use of $C P E$ to directly evaluate the capacitive response of electrochemical interfaces has been a matter of controversy in the scientific literature, which can be most probably ascribed to the different kinds of physical-chemical phenomena at their origin ${ }^{33}$, even though, for corroding electrodes they are most frequently ascribed to surface inhomogeneity. In a recent work, Orazem et al. ${ }^{34}$ proposed some graphical representations that can enhance the interpretation of EIS data. One of them consists in plot the modulus of the imaginary part of the impedance as a function of the frequency, both in logarithmic scale. The slope of this plot in the high frequency region gives $(-\alpha)$ without the need to fit the EIS data with an electrical equivalent circuit. Figure 6 presents this plot for the EIS data acquired in the solution containing $1.112 \mathrm{~g} \mathrm{~L}^{-1}$ of cocoa bark extract, whereas Table 3 presents a comparison between " $\alpha$ " values determined by the two methodologies: EEC fitting and the methodology proposed by Orazem et al. ${ }^{34}$. The results show that they provide essentially the same results, indicating that, if a meaningful physical model to interpret the electrochemical system is available ${ }^{35}$, the two methodologies are equivalent.

Orazem et al. ${ }^{34}$ proposed also a manner to determine an effective $C P E$ coefficient $\left(Q_{\text {eff }}\right)$ when $\alpha \neq 1$, which is given by Eq. (5). According to the authors ${ }^{34}$ the asymptote to the straight line in the high frequency region of the plot of $Q_{\text {eff }}$ versus the frequency, both in logarithmic scale, would allow to determine the true value of the $C P E$ coefficient.

Figure 7 depicts the graphical determination of $Q_{\text {eff }}$ for the EIS data acquired in the solution containing 1.112 g.L $\mathrm{L}^{-1}$ of cocoa bark extract, whereas Table 3 shows the values for the three EIS responses discussed in this section of the manuscript. It can be observed that $Q_{\text {eff }}$ is smaller when the inhibitors are added to the solution, and that within the confidence level of a graphical determination, $Q_{\text {eff }}$ for the EIS data acquired in the cocoa bark extract and BTAH containing solutions were equals.

$$
Q_{e f f}=\sin \left(\frac{\alpha \pi}{2}\right) \frac{-1}{Z^{\prime \prime}(f)(2 \pi f)}
$$

\begin{tabular}{|c|c|c|c|c|c|c|}
\hline & $\begin{array}{c}\text { Concentrationg } \\
\mathbf{L}^{-1}\end{array}$ & $R s\left[\Omega \mathrm{cm}^{2}\right]$ & $\operatorname{Rct}\left[\Omega \mathrm{cm}^{2}\right]$ & $\begin{array}{c}C P E-T\left[\mathrm{~F} \mathrm{~cm}^{-2}\right. \\
\left.\mathrm{s}^{(\mathrm{n}-1)}\right]\end{array}$ & $\alpha$ & $I E \%$ \\
\hline without inhibitor & & 5.5 & 395 & $2.610^{-4}$ & 0.74 & - \\
\hline $\begin{array}{c}\text { cocoa bark } \\
\text { extract }\end{array}$ & 1.112 & 6.9 & 2117 & $3.210^{-5}$ & 0.87 & 81.3 \\
\hline BTAH & 1.112 & 8.1 & 2292 & $3.610^{-5}$ & 0.89 & 82.3 \\
\hline
\end{tabular}

Table 2. Results for the parameters obtained from the fitting of the EIS diagrams presented in Figure 4 with the equivalent electrical circuit of Figure 5. 


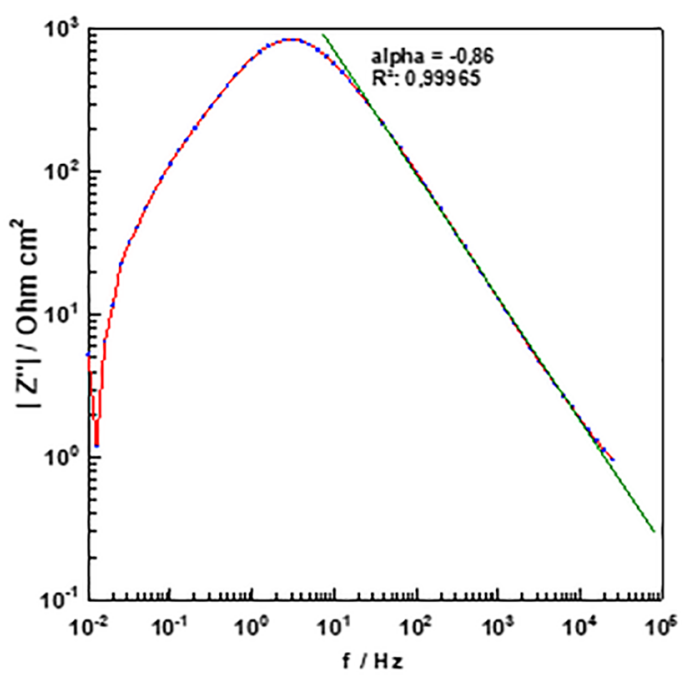

Figure 6. Imaginary part of the impedance as a function of frequency for CS - ASTM 1020 after immersion for $90 \mathrm{~min}$ in $18.23 \mathrm{~g} \mathrm{~L}^{-1} \mathrm{HCl}$ solution in the presence of $1.112 \mathrm{~g} \mathrm{~L}^{-1}$ cocoa bark extract.

Table 3. Values of the graphical and fit methods for the EIS data for CS - ASTM 1020 in $18.23 \mathrm{~g} \mathrm{~L}^{-1} \mathrm{HCl}$ solution in the absence and in the presence of $1.112 \mathrm{~g} \mathrm{~L}^{-1}$ of inhibitor. $\mathrm{C}_{\mathrm{dl}}$ calculated with Eq. (6) with $\alpha$ from the graphical determination method.

\begin{tabular}{|c|c|c|c|c|}
\hline Inhibitor & $\begin{array}{r}\alpha(\text { EIS } \\
\text { fitting) }\end{array}$ & $\begin{array}{l}\alpha \text { (graphical } \\
\text { method) }\end{array}$ & $\begin{array}{l}Q_{\text {eff }}\left(\Omega^{-1}\right. \\
\left.\mathbf{c m}^{-2} \mathbf{s}^{\mathrm{n}}\right)\end{array}$ & $\begin{array}{c}C_{\mathrm{dl}}\left(\mathrm{mF} \mathrm{cm} \mathrm{cm}^{-2}\right) \\
\text { (graphical } \\
\text { method) }\end{array}$ \\
\hline Without & 0.74 & 0.77 & 0,0003 & 44 \\
\hline $\begin{array}{l}\text { Cocoa } \\
\text { bark } \\
\text { extract }\end{array}$ & 0.87 & 0.86 & 0,00004 & 10,5 \\
\hline BTAH & 0.89 & 0.88 & 0,00004 & 13,3 \\
\hline
\end{tabular}

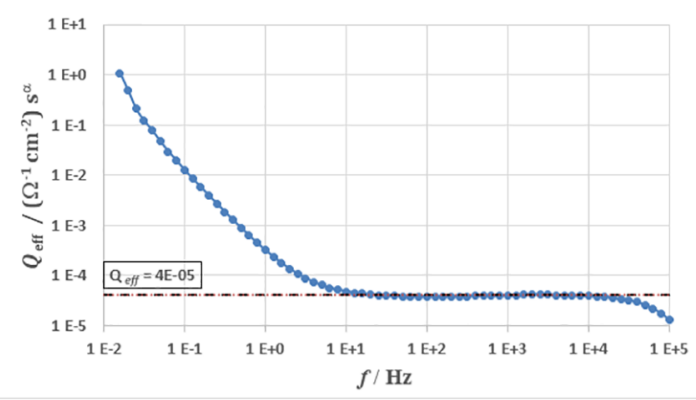

Figure 7. Effective CPE coefficient $\left(\mathrm{Q}_{\text {eff }}\right)$ defined from Eq. (5) for CS - ASTM 1020 steel after immersion for $90 \mathrm{~min}$ in $18.23 \mathrm{~g}$ $\mathrm{L}^{-1} \mathrm{HCl}$ solution in the presence of $1.112 \mathrm{~g} \mathrm{~L}^{-1}$ cocoa bark extract.

Finally, considering that the EIS response of CS in all the tested solutions consists of a single capacitive loop ascribed to the charge transfer reaction, the double layer capacity $\left(C_{\mathrm{d} 1}\right)$ was calculated using the formula proposed by Brug et al. (Eq. (6) $)^{36}$ using the $Q_{\text {eff }}$ values determined from Eq. (5), and the $\alpha$ values from the graphical determination methodology. The results are compiled in Table 3. It can be observed that, after the corrections, the capacity determined from the EIS data obtained in the inhibitor-free solution is very close to the $C_{\mathrm{dl}}$ value (about $50 \mu \mathrm{F} \mathrm{cm} \mathrm{cm}^{-2}$ ), whereas, when inhibitors are added to the solution it decreases. This latter finding can be ascribed both to the adsorption of the organic molecules to the electrode surface, displacing water molecules and/or chloride ions ${ }^{32}$, which diminishes the double layer dielectric constant, and to the increased thickness of the electric double layer due to the bigger size of the adsorbed organic molecules ${ }^{30,37}$.

$$
C_{d l}=Q_{e f f}^{1 / \alpha} \times\left(\frac{1}{R_{s}}+\frac{1}{R_{c t}}\right)^{(\alpha-1) / \alpha}
$$

\subsection{Polarization curves}

Figure 8 presents the potentiodynamic polarization curves obtained in the absence and in the presence of different amounts of the cocoa bark extract. The results corroborate with the previous tests and show that the addition of the extract to the test solution reduces CS corrosion, and that this effect is enhanced with increasing inhibitor amount. They also demonstrate that the inhibitor acts by hindering the cathodic reaction. In addition, the slopes of the cathodic and anodic branches almost does not change in the presence of the inhibitor, which is another evidence that the addition of the cocoa bark extract does not change the corrosion mechanism.

The potentiodynamic polarization curves obtained in the $18.23 \mathrm{~g} \mathrm{~L}^{-1} \mathrm{HCl}$ solution with $1.112 \mathrm{~g} \mathrm{~L}^{-1}$ of either cocoa bark extract or BTAH are presented in Figure 9. These curves were acquired after the completion of the EIS experiments followed by $5 \mathrm{~min}$ stabilization of the OCP. They show very similar behavior and confirm that both inhibitors act by polarizing the cathodic branch of the interfacial reaction. Therefore, the hydrogen reduction reaction is hindered and the corrosion potential is shifted to the negative direction with a consequent diminution of the corrosion current density. The diagrams also show that the reactions are slightly more polarized in the BTAH-containing electrolyte, pointing to higher efficacy.

The corrosion current densities $\left(i_{\text {corr }}\right)$ were determined using the Tafel extra polation method and the results are depicted in Table 1. From these data, the inhibition efficiencies were determined by Eq. (7):

$$
I E \%=\frac{i_{\text {corro }}-i_{\text {corr }}}{i_{\text {corro }}} .100
$$

where $i_{\text {corro }}$ is the corrosion current density of CS-ASTM 1020 in the absence of inhibitors and $i_{\text {corr }}$ the corrosion current density in their presence.

The IE results presented in Table 1 are in fully accordance with the other techniques, and can be summarized as follows: IE of cocoa bark extract increases with inhibitor concentration and BTAH is slightly more efficient than the 


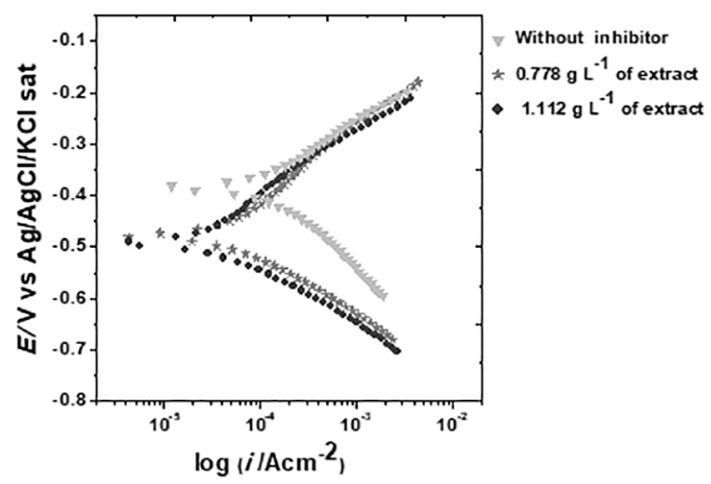

Figure 8. Potentiodynamic polarization curves for CS - ASTM 1020 after $120 \mathrm{~min}$ immersion in $18.23 \mathrm{~g} \mathrm{~L}^{-1} \mathrm{HCl}$ solution in the absence and in the presence of different amounts of cocoa bark extract.

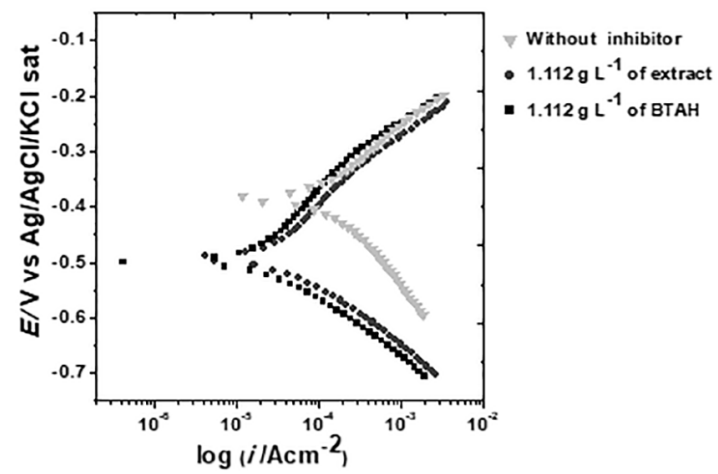

Figure 9. Potentiodynamic polarization curves for CS - ASTM 1020 after $120 \mathrm{~min}$ immersion in $18.23 \mathrm{~g} \mathrm{~L}^{-1} \mathrm{HCl}$ solution in the absence and in the presence of $1.112 \mathrm{~g} \mathrm{~L}^{-1}$ of inhibitors.

extract. In addition, the IE as determined from the Tafel extrapolation method and from the gravimetric tests show high degree of concordance.

\subsection{SEM Characterization}

Images of the CS-ASTM 1020 surface were obtained by scanning electron microscopy (SEM) after EIS analysis (90
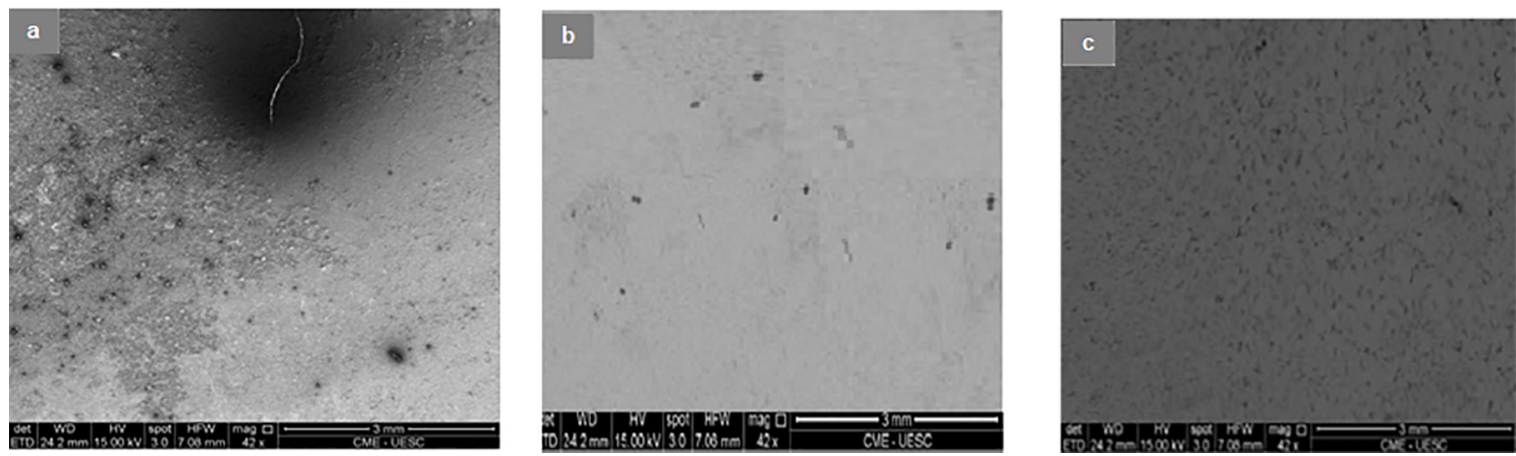

Figure 10. CS - ASTM 1020 surface SEM images after $90 \mathrm{~min}$ immersion in $18.23 \mathrm{~g} \mathrm{~L}^{-1} \mathrm{HCl}$ solution in the absence of inhibitor (a) and in the presence of $1.112 \mathrm{~g} \mathrm{~L}^{-1}$ of BTAH (b) or cocoa bark extract (c). 10a) and in the presence of $1.112 \mathrm{~g} \mathrm{~L}^{-1}$ of BTAH (Fig. 10b) or of cocoa bark extract (Fig. 10c). By comparing the three figures, it can be verified that there was generalized corrosion in the absence of the inhibitors (Fig. 10a), whereas when inhibitors were added to the test electrolyte the corrosive process was reduced (Figs. 10b and c) ${ }^{6,16}$. Through energy dispersive spectroscopy analysis (EDS), it was possible to obtain evidences of the presence of some chemical elements at the substrate surface, such as phosphorus, sulfur and nitrogen (Fig. 11b), which are characteristics of the composition of inhibitors, as already discussed in the FTIR analysis. This cocoa bark extract can adsorb on the CS surface ${ }^{6,16}$, and, as evidenced in the results of the corrosion tests, can effectively block the interfacial process by hindering the cathodic process. It must be emphasized that these elements were not present in the EDS spectrum for the CS-ASTM 1020 after immersion in the test solution in the absence of inhibitors, as shown in Fig. 11a.
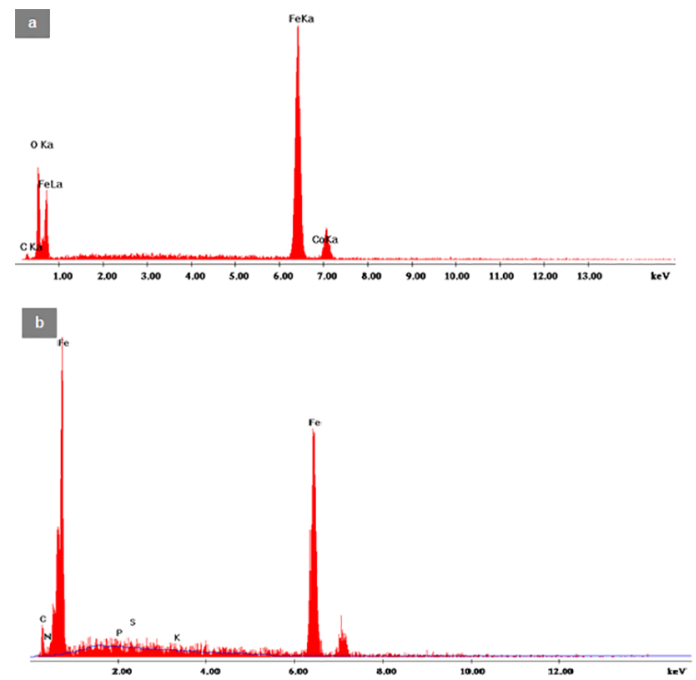

Figure 11. EDS spectra of the surface of CS-ASTM 1020 in the absence of inhibitor (a) and in the presence of $1.112 \mathrm{~g} \mathrm{~L}^{-1}$ of cocoa bark extract after $90 \mathrm{~min}$ immersion in $18.23 \mathrm{~g} . \mathrm{L}^{-1} \mathrm{HCl}$ solution. min immersion in $\mathrm{HCl} 18.23 \mathrm{~g} \mathrm{~L}^{-1}$ solution) without (Fig. indicates that molecules with inhibitory properties of the 
Higher magnification SEM micrographs were obtained after the gravimetric tests $(120 \mathrm{~min}$ immersion in $\mathrm{HCl}$ $18.27 \mathrm{~g} \mathrm{~L}^{-1}$ solution) in the absence and in the presence of inhibitors (Fig. 12). At local scale the images show an intense corrosive attack of the CS surface in the inhibitor free solution (Fig. 12a). On the other hand, a cracked mud corrosion product layer is deposited on the sample exposed to the BTAH containing solution (Fig. 12b). From the IE results exhibited in Table 1 it is possible to suppose that this structure must act as a barrier to electrolyte penetration protecting the substrate from corrosion, as already verified in other aggressive media ${ }^{28}$. Finally, the sample exposed to the solution containing $1.112 \mathrm{~g} \mathrm{~L}^{-1}$ of the cocoa bark extract show a quite smooth surface, indicating that the corrosion protection afforded by this inhibitor is not based on the precipitation of a corrosion product layer, but rather to an adsorption process. The EDS spectrum from this sample surface (Fig. $12 \mathrm{~d}$ ) also showed the presence of P, S and N indicating the presence of a surface film.
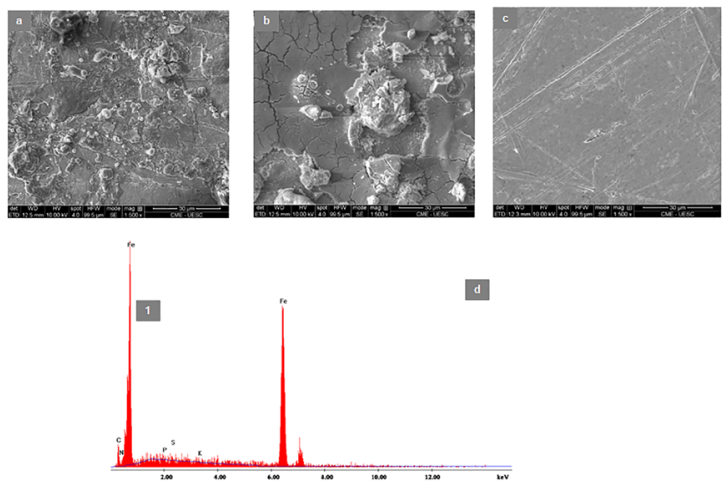

Figure 12. SEM images of CS-ASTM 1020 surface after $120 \mathrm{~min}$ immersion in $18.23 \mathrm{~g} \mathrm{~L}^{-1} \mathrm{HCl}$ solution in the absence (a) and in the presence of $1.112 \mathrm{~g} \mathrm{~L}^{-1}$ of benzotriazole (b) or cocoa bark extract (c). EDS spectrum of the surface of the latter sample (d).

\section{Conclusions}

In the present work, the efficiency of cocoa bark extract towards the corrosion inhibition of CS-ASTM 1020 in $18.23 \mathrm{~g}$ $\mathrm{L}^{-1} \mathrm{HCl}$ solution was investigated and compared with BTAH.

The results of the weight loss and of the electrochemical tests showed that the studied natural corrosion inhibitor was effective in hindering the corrosion of CS-ASTM 1020.

The EDS results supported by enhanced interpretation of the EIS data indicated that, in the presence of the cocoa bark extract, an adsorbed layer is formed on the sample surface, which hinders the cathodic reaction, as showed by the polarization curves. It is likely that the adsorbed layer is formed by organic compounds containing nitrogen heteroatom's as indicated by FTIR analysis and EDS evidences.

Inhibiting efficiency calculations made from weight loss, EIS and polarization experiments showed that the cocoa bark extract is only slightly less efficient than BTAH for inhibition of CS-ASTM 1020 corrosion in $18.23 \mathrm{~g} \mathrm{~L}^{-1} \mathrm{HCl}$ solution, showing that this natural inhibitor can be an effective option to control corrosion of carbon steel in acidic media.

\section{Acknowledgements}

The authors would like to thank the following laboratories: LAMMA (Laboratory of Materials and Environment of the State University of Santa Cruz), BIOMA (Bioenergy and Environment) and CAPES (Higher Education Personnel Improvement Coordination) for the financial support.

\section{References}

1. Ahamed I, Prasad R, Quraishi MA. Thermodynamic, electrochemical and quantum chemical investigation of some Schiff bases as corrosion inhibitors for mild steel in hydrochloric acid solutions. Corrosion Science. 2010;52(3):933-942.

2. Singh AK, Quraishi MA. Effect of Cefazolin on the corrosion of mild steel in $\mathrm{HCl}$ solution. Corrosion Science. 2010;52(1):152160.

3. Gomma GK. Corrosion inhibition of steel by benzotriazole in sulphuric acid. Materials Chemistry and Physics. 1998;55(3):235240 .

4. Bendahou M, Benadellah M, Hammouti B. A study of rosemary oil as a green corrosion inhibitor for steel in $2 \mathrm{M} \mathrm{H}_{3} \mathrm{PO}_{4}$. Pigment \& Resin Technology. 2006;35(2):95-100.

5. Ebenso EE, Eddy NO, Odiongenyi AO. Corrosion inhibitive properties and adsorption behavior of ethanol extract of Piper guinensis as a green corrosion inhibitor for mild steel in $\mathrm{H}_{2} \mathrm{SO}_{4}$. African Journal of Pure and Applied Chemistry. 2008;2(11):107115.

6. Pereira SSAA, Pêgas MM, Fernández TL, Magalhães M, Schöntag TG, Lago DC, et al. Inhibitory action of aqueous garlic peel extract on the corrosion of carbon steel in $\mathrm{HCl}$ solution. Corrosion Science. 2012;65:360-366.

7. Gomes AWM. Inibidores naturais de corrosão extraídos em vegetais tropicais [Thesis]. Campinas: Universidade Estadual de Campinas (UNICAMP); 1999.

8. Ayeni FA, Alawode S, Joseph D, Sukop P, Olawuyi V, Alonge $\mathrm{TE}$, et al. Investigation of Sida acuta (WireWeed) plant extract as corrosion inhibitor for aluminium-copper-magnessium alloy in acidic medium. Journal of Minerals and Materials Characterization and Engineering. 2014;2(4):286-291.

9. Khaled KF. Molecular simulation, quantum chemical calculations and electrochemical studies for inhibition of mild steel by triazoles. Electrochimica Acta. 2008;53(9):3484-3492.

10. Liu S, Xu N, Duan J, Zeng Z, Feng Z, Xiao R. Corrosion inhibition of carbon steel in tetra-n-butylammonium bromide aqueous solution by benzotriazole and $\mathrm{Na}_{3} \mathrm{PO}_{4}$. Corrosion Science. 2009;51(6):1356-1363.

11. Jakeria MR, Fazal MA, Haseeb ASMA. Effect of corrosion inhibitors on corrosiveness of palm biodiesel. Corrosion Engineering, Science and Technology. 2015;50(1):56-62. 
12. Lake DL. Approaching environmental acceptability in cooling water corrosion inhibition. Corrosion Prevent Control. 1988;35(4):113-115.

13. Ibrahim TH, Chehade Y, Zour MA. Corrosion inhibition of mild steel using potato peel extract in $2 \mathrm{M} \mathrm{HCl}$ solution. International Journal of Electrochemical Science. 2011;6(12):6542-6556.

14. Garai S, Garai S, Jaisankar P, Singh JK, Elango A. A comprehensive study on crude methanolic extract of Artemisia pallens (Asteraceae) and its active component as effective corrosion inhibitors of mild steel in acid solution. Corrosion Science. 2012;60:193-204.

15. Abdallah M. Guar Gum as corrosion inhibitor for carbon steel in sulphuric acid solutions. Portugaliae Electrochimica Acta. 2004;22(2):161-175.

16. Abiola OK, James AO. The effects of Aloe vera extract on corrosion and kinetics of corrosion process of zinc in $\mathrm{HCl}$ solution. Corrosion Science. 2010;52(2):661-664.

17. Davis GD, von Fraunhofer JA, Krebs LA, Dacres CM. The use of tobacco extracts as corrosion inhibitor. In: Proccedings of Corrosion 2001; 2011 Mar 11-16; Houston, TX, USA. p. 58-60.

18. Saleh RM, Ismail AA, Hosar EL. Corrosion Inhibition by Naturally Occurring Substances: VII. The effect of aqueous extracts of some leaves and fruit-peels on the corrosion of steel, $\mathrm{Al}, \mathrm{Zn}$ and $\mathrm{Cu}$ in acids. British Corrosion Journal. 1982;17(3):131-135.

19. Zerga B, Sfaira M, Rais Z, Ebntouhami M, Taleb M, Hammouti B, et al. Lavender oil as an ecofrindly inhibitor for mild steel in $1 \mathrm{M} \mathrm{HCl}$. Matériaux \& Techniques. 2009;97(5):297-305.

20. Fadel F, Hmamou DB, Salghi R, Chebli B, Benali O, Zarrouk A, et al. Antifungal activity and anti-corrosion inhibition of origanum compactum extracts. International Journal of Electrochemical Science. 2013;8(9):11019-11032.

21. Bravo L. Polyphenols: Chemistry, Dietary Sources, Metabolism and Nutritional Significance. Nutrition Reviews. 1998;56(11):317333.

22. Berkovic K, Radojcic I, Delonga K, Vorkapic-Furac J. Polyphenolsenvironmentally friendly corrosion inhibitors of tin. Current Studies of Biotechnology, Vol. III - Food. 2003;3:365-372.

23. ASTM International. ASTM G1 - 90(1999)e1 - Standard Practice for Preparing, Cleaning, and Evaluating Corrosion Test Specimens. West Conshohocken: ASTM International; 1999.

24. Zucchi F, Omar IH. Plant extracts as corrosion inhibitors of mild steel in HCl solutions. Surface Technology. 1985;24(4):391-399.

25. Oguize EE, Okolue BN, Ogukwe CE, Onuchukwu AI. Studies on the inhibitive action of methylene blue dye on aluminium corrosion in $\mathrm{KOH}$ solution. Journal of Corrosion Science and Technology. 2004;1:88-91.

26. Zhao J, Chen G. The synergistic inhibition effect of oleic-based imidazoline and sodium benzoate on mild steel corrosion in a $\mathrm{CO}_{2}$-saturated brine solution. Electrochimica Acta. 2012;69:247255 .

27. Chevalier M, Robert F, Amusant N, Traisnel M, Roos C, Lebrini M. Enhanced corrosion resistance of mild steel in 1 $\mathrm{M}$ hydrochloric acid solution by alkaloids extract from Aniba rosaeodora plant: Electrochemical, phytochemical and XPS studies. Electrochemical Acta. 2014;131:96-105.

28. Markhali BP, Naderi R, Sayebani M, Mahdavian M. Corrosion inhibition of some azole derivatives on carbon steel in hydrochloric acid solution. Anti-Corrosion Methods and Materials. 2014;61(4):300-306.

29. Duval S, Keddam M, Sfaira M, Srhiri A, Takenouti H. Electrochemical impedance spectroscopy of epoxy-vinyl coating in aqueous medium analyzed by dipolar relaxation polymer. Journal of The Electrochemical Society. 2002;149(11):520-529.

30. Banerjee S, Srivastava V, Singh MM. Chemically modified natural polysaccharide as green corrosion inhibitor for mild steel in acidic medium. Corrosion Science. 2012;59:35-41.

31. Khaled KF. New synthesized guanidine derivative as a green corrosion inhibitor for mild steel in acidic solutions international. Journal Electrochemical Science. 2008;3(4):462-475.

32. Ghailane T, Balkhmima RA, Ghailane R, Souizi A, Touir R, EbnTouhami M, et al. Experimental and theoretical studies for mild steel corrosion inhibition in $1 \mathrm{M} \mathrm{HCl}$ by two new benzothiazine derivatives. Corrosion Science. 2013;76:317-324.

33. Jorcin JB, Orazem ME, Pébère N, Tribollet B. CPE analysis by local electrochemical impedance spectroscopy. Electrochimica Acta. 2006;51(8-9):1473-1479.

34. Orazem ME, Pébère N, Tribollet B. Enhanced graphical representation of electrochemical impedance data. Journal of The Electrochemical Society. 2006;153(4):129-136.

35. Bonora PL, Deflorian F, Fedrizzi L. Electrochemical impedance spectroscopy as a tool for investigating underpaint corrosion. Electrochimica Acta. 1996;41(7-8):1073-1082.

36. Brug GJ, Ven Den Eeden ALG, Sluyters-Rehbach M, Sluyters $\mathrm{JH}$. The analysis of electrode impedances complicated by the presence of a constant phase element. Journal of Electroanalytical Chemistry and Interfacial Electrochemistry. 1984;176(12):275-295

37. Moretti G, Guidi F, Fabris F. Corrosion inhibition of the mild steel in $0.5 \mathrm{M} \mathrm{HCl}$ by 2-butyl-hexahydropyrrolo[1,2-b][1,2] oxazole. Corrosion Science. 2013;76:206-218. 